\title{
The prevalence of probable neuropathic pain in the US: results from a multimodal general-population health survey
}

This article was published in the following Dove Press journal:

Journal of Pain Research

I November 2017

Number of times this article has been viewed

\author{
Marco D DiBonaventura' \\ Alesia Sadosky ${ }^{2}$ \\ Kristen Concialdi' \\ Markay Hopps ${ }^{2}$ \\ Ian Kudel' \\ Bruce Parsons ${ }^{2}$ \\ Joseph C Cappelleri ${ }^{3}$ \\ Patrick Hlavacek ${ }^{2}$ \\ Andrea H Alexander ${ }^{2}$ \\ Brett R Stacey ${ }^{4}$ \\ John D Markman ${ }^{5}$ \\ John T Farrar ${ }^{6}$ \\ 'Health Outcomes Practice, Kantar \\ Health, ${ }^{2}$ Pfizer Inc, New York, NY, \\ ${ }^{3}$ Pfizer Inc, Groton, CT, ${ }^{4}$ University of \\ Washington, Seattle, WA, ${ }^{5}$ University \\ of Rochester School of Medicine and \\ Dentistry, Rochester, NY, 'University \\ of Pennsylvania Perelman School of \\ Medicine, Philadelphia, PA, US
}

Background: The prevalence of neuropathic pain $(\mathrm{NeP})$ has been estimated within specific health conditions; however, there are no published data on its broad prevalence in the US. The current exploratory study addresses this gap using the validated PainDetect questionnaire as a screener for probable NeP in a general-population health survey conducted with a multimodal recruitment strategy to maximize demographic representativeness.

Materials and methods: Adult respondents were recruited from a combination of Internet panels, telephone lists, address lists, mall-based interviews, and store-receipt invitations using a random stratified-sampling framework, with strata defined by age, sex, and race/ethnicity. Older persons and minorities were oversampled to improve prevalence estimates. Results were weighted to match the total adult US population using US Census data. Demographic information was collected, and respondents who experienced physical pain in the past 12 months completed the PainDetect and provided additional pain history. A cutoff score of 19 or greater on the PainDetect was used to define probable NeP.

Results: A total of 24,925 respondents (average response rate $2.5 \%$ ) provided demographic data (52.2\% female, mean age 51.5 years); 15,751 respondents reported pain (63.7\%), of which 2,548 (15.7\%, 95\% confidence interval 14.9\%-16.5\%) had probable NeP based on the PainDetect, which was $10 \%$ (95\% confidence interval $9.5 \%-10.5 \%)$ of all respondents. Among those reporting pain, the prevalence of probable NeP among Blacks and Hispanics was consistently higher than Whites in each age- and sex group. The highest prevalence among those with pain was among male Hispanics 35-44 years (32.4\%) and 45-54 years (24.2\%) old. The most commonly used medications reported by those with probable NeP were nonsteroidal anti-inflammatory drugs (44.2\%), followed by weak opioids (31.7\%), antiepileptics (10.9\%), and strong opioids (10.9\%). Conclusion: This is the first study to provide an estimate of the prevalence of probable $\mathrm{NeP}$ in the US, showing significant variation by age and ethnicity.

Keywords: neuropathic pain, prevalence, pain types, epidemiology

\section{Introduction}

According to the International Association for the Study of Pain, neuropathic pain $(\mathrm{NeP})$ is characterized by a "pain arising as a direct consequence of a lesion or disease of the somatosensory system". ${ }^{1}$ However, identification of $\mathrm{NeP}$ is challenging, given its association with other pain processes and the absence of a "gold standard" diagnostic test. Not surprisingly, it can be difficult to treat effectively and is associated with significant impairments in health-related quality of life along with a substantial economic burden. ${ }^{2,3}$

The existing literature has primarily investigated the epidemiology of NeP within the context of specific diseases, such as cancer, diabetic peripheral neuropathy (DPN), 
and chronic low-back pain (CLBP). For example, systematic reviews of patients with cancer have reported prevalence rates of $\mathrm{NeP}$ at $19 \%,{ }^{4}$ with similar estimates $(20 \%)$ among patients with type 2 diabetes. ${ }^{5-9}$ However, as obesity rates and associated comorbid conditions, such as diabetes and CLBP (resulting from lumbar surgery interventions), continue to increase in the US, the total number of people experiencing NeP is likely to continue to grow. ${ }^{10-13}$ These trends highlight the need to examine the prevalence of $\mathrm{NeP}$ broadly, rather than from a disease-specific perspective.

In spite of the challenges associated with defining $\mathrm{NeP}$, estimating the population prevalence is critical for a number of reasons, including but not limited to quantifying the potential societal burden, calculating the potential health care needs of this population, and guiding health policies. This is particularly pertinent, given that the majority of patients with $\mathrm{NeP}$ are treated by primary care physicians in the community, who do not necessarily specialize in the diagnosis or management of $\mathrm{NeP}^{14}$

To date, the largest NeP-prevalence study conducted in the US, using data from a survey, phone, and clinical examinations, found a prevalence rate of $9.8 \%$ among adult Minnesotans. ${ }^{15}$ The current exploratory study estimates the prevalence of $\mathrm{NeP}$, both overall and among those with pain, using data collected from a nationwide survey.

\section{Materials and methods Sampling}

Data for this study were collected using a cross-sectional survey of adults in the US (aged 18 years and older). The sample size was calculated to ensure a level of precision in each sex-by-age-by ethnicity stratum (the smallest anticipated unit for prevalence calculations) that would not exceed $\pm 2.5 \%$. Subsequently, there is a $95 \%$ probability that the true population prevalence resides within $2.5 \%$ of the reportedprevalence estimate from our sample. This sample size was larger than what would be required if the true prevalence was around $20 \%$. Participants were recruited via Internet, mail, telephone, shopping-mall interception, and retail store-receipt solicitation. This multimodal approach was used to maximize external validity and avoid potential biases that could occur if only a single approach were used. The frequency of each method was selected to enhance study feasibility and minimize recruiting time (eg, fewer respondents were recruited via mailing lists, because it requires more time and effort to receive responses than other modalities, such as the Internet).

The sampling frame was designed to ensure adequate numbers of participants were included within each age, sex, and race/ethnicity stratum so that reasonable populationprevalence estimates could be derived. Older ( 65 years of age and above) and minority respondents were oversampled relative to their true proportions in the population to ensure that there were at least 100 participants in each cell (see Table 1). Sampling weights were calculated to adjust the demographic characteristics of the sample to reflect the total adult US population.

\section{Recruitment}

Participants were recruited from August 2014 to October 2014. Members from several Internet panels (Lightspeed, ${ }^{16}$ Survey Sampling International, ${ }^{17}$ and Toluna ${ }^{18}$ ) were recruited for this study using previously established methods for mail and Internet surveys ${ }^{19}$ and subgroup solicitation..$^{20}$ Potential participants were organized into demographic strata (eg, non-Hispanic White males aged 18-34 years, non-Hispanic White males aged 35-44 years). Then, random sampling was used to identify potential participants within each stratum. Selected individuals were emailed an invitation to complete the survey. Those who clicked on the link were taken to a statement of informed consent, which described the study as a general health survey. Consenters completed an online questionnaire.

Mailing and calling lists (purchased from Marketing Systems Group) ${ }^{21}$ compiled from phone books and other sources were also used to recruit participants. These lists totaled over 153 million unique records. Potential respondents were first identified by age, sex, and race/ethnicity, and then either randomly mailed or called to ascertain interest. Those on the mailing list $(n=80,004)$ were sent a paper version of the statement of informed consent, the survey, and a self-addressed stamped envelope so that they could return the materials to the research team. A total of 181,770 people on the telephone list were contacted by trained interviewers. Those who were willing to participate and who reported experiencing any pain in the previous 12 months were then asked whether they would prefer to complete the remainder of the survey using the Internet or receive materials by mail, since the PainDetect has not been validated for telephone administration.

To increase sample size, two additional recruitment methods were implemented during the last year of the study. In the first, trained researchers recruited a convenience sample of participants from 20 different shopping malls across the US. Those who were interested completed the informed consent and survey via computer. In the second modality, customers at pharmacies, grocery stores, and convenience stores 
Table I Demographic characteristics of the study sample $(n=24,925)$

\begin{tabular}{|c|c|c|c|c|c|}
\hline \multicolumn{2}{|c|}{ Demographic characteristic } & \multicolumn{2}{|c|}{ Unweighted } & \multicolumn{2}{|l|}{ Weighted } \\
\hline & & \multirow{2}{*}{$\begin{array}{l}\mathbf{n} \\
11,925\end{array}$} & \multirow{2}{*}{\begin{tabular}{l|l|}
$\%$ \\
47.8
\end{tabular}} & \multirow{2}{*}{$\begin{array}{l}\mathbf{n} \\
116,560,000\end{array}$} & \multirow{2}{*}{$\begin{array}{l}\% \\
48.2\end{array}$} \\
\hline Sex & Male & & & & \\
\hline & Female & 13,000 & 52.2 & $125,270,000$ & 51.8 \\
\hline \multirow[t]{6}{*}{ Age, years } & $18-34$ & 5,400 & 21.7 & $72,5 \mid 4,917$ & 30 \\
\hline & $35-44$ & 3,402 & 13.6 & $39,698,557$ & 16.4 \\
\hline & $45-54$ & 4,267 & 17.1 & $42,656,469$ & 17.6 \\
\hline & $55-64$ & 4,473 & 17.9 & $40,556,004$ & 16.8 \\
\hline & $65-74$ & 5,425 & 21.8 & $27,363,123$ & 11.3 \\
\hline & $75+$ & 1,958 & 7.9 & $19,040,479$ & 7.9 \\
\hline \multirow[t]{4}{*}{ Race } & White & 7,417 & 29.8 & $156,760,000$ & 64.8 \\
\hline & Hispanic & 5,858 & 23.5 & $37,577,888$ & 15.5 \\
\hline & Black & 6,453 & 25.9 & $28,38 I, 68 I$ & 11.7 \\
\hline & Other & 5,197 & 20.9 & $19,113,108$ & 7.9 \\
\hline Questionnaire & Internet & 15,088 & 60.5 & $139,460,000$ & 57.7 \\
\hline \multirow[t]{4}{*}{ modality } & Telephone & 2,907 & 11.7 & $36,672,669$ & 15.2 \\
\hline & Mail & 982 & 4 & $14,568,067$ & 6 \\
\hline & Mall intercept & 5,338 & 21.4 & $39,342,717$ & 16.3 \\
\hline & Store-receipt invitation* & 590 & 2.4 & $\mid I, 406,801$ & 4.7 \\
\hline \multirow[t]{4}{*}{ Region** } & East & 4,554 & 18.3 & $44,367,561$ & 18.4 \\
\hline & Midwest & 5,218 & 20.9 & $58,095,899$ & 24 \\
\hline & South & 8,820 & 35.4 & $80,982,310$ & 33.5 \\
\hline & West & 6,286 & 25.2 & $57,837,823$ & 23.9 \\
\hline
\end{tabular}

Notes: *Store-receipt invitation refers to a method by which respondents were invited to participate through an Internet link on a store receipt that they received at participating retailers (eg, pharmacies, grocery stores); **State and thus region information was unavailable for 47 respondents.

were supplied with store receipts that included an invitation encouraging them to participate in the study. It directed them to a website that included the statement of informed consent and (upon completion) a link to the survey. All respondents were financially compensated between $\$ 1$ and $\$ 10$, depending on the recruitment modality. The study materials were reviewed and approved by an independent institutional review board (Sterling IRB, Atlanta, GA; protocol 161101387-2).

\section{Data handling}

For participants completing the survey via the Internet, data entry was completed instantaneously as the respondent answered the survey questions. For participants recruited via telephone, their data were entered manually into the online survey by the telephone interviewer. Respondents participating by mail had their responses manually entered into the database. All data were stored in a relational database, which housed the questionnaire responses and allowed for direct export into statistical software programs. With respect to analysis, all programming and outputs were reviewed by at least two independent researchers.

\section{Measures}

All respondents provided their sex, age, race/ethnicity, state of residence, and whether they had experienced any of 19 health conditions or any pain within the last 12 months. Those who self-reported experiencing any pain within the last 12 months were asked to complete the PainDetect, a validated $\mathrm{NeP}$-screening tool and other questions, including demographic, physical, and psychiatric comorbidities, pain types, and medication use.

The PainDetect is a screening tool used to assess the presence of NeP. ${ }^{22}$ Psychometric analyses indicate it can be used in a number of NeP subpopulations, including CLBP, ${ }^{22}$ peripheral nerve damage, ${ }^{23} \mathrm{HIV},{ }^{24-26}$ posttrauma/postsurgical injury, ${ }^{24-26}$ spinal cord injury, ${ }^{24-26}$ small-fiber neuropathy, ${ }^{24-26}$ neck and shoulder pain, ${ }^{23}$ and osteoarthritis of the knee, ${ }^{27}$ as well as a heterogeneous NeP sample. ${ }^{28}$ The questionnaire does not perform as well in people with neck/upper-limb pain ${ }^{29}$ or fibromyalgia, who were not included in this study. ${ }^{30}$

Like other NeP-screening measures, the PainDetect includes verbal descriptors and clinical characteristics. It is comprised of three components: pain intensity, pain-course pattern, and gradations of pain. For the first part, respondents used a $0-10$ numerical rating scale to report their pain at the time they were completing the questionnaire. Two other items asked participants to use the same rating scale to report the strongest pain and average pain during the preceding 4 weeks. Then, four graphs were presented, and the respondent was asked to choose which best described the course of their 
pain. Each graph was accompanied by one of the following labels: "persistent pain with slight fluctuations", "persistent pain with pain attacks", "pain attacks without pain between them", or "pain attacks with pain between them". The third part asked respondents to rate the intensity of seven different pain sensations (eg, burning, tingling) on a scale from 0 (never) to 5 (very strongly).

A total PainDetect score for each respondent was generated by summing the number of points earned on each of the three sections. The screening tool has been shown to have over $80 \%$ sensitivity and specificity in paper-and-pencil form, and responses between that format and electronic administration of the instrument were found to be equivalent. ${ }^{31}$ PainDetect scores can be categorized into three groups: unlikely NeP (0-12), "unlikely" (13-18), and positive/likely NeP ( $\geq 19) .{ }^{22}$ Since this study focused on estimating the prevalence of NeP, scores were dichotomized into "unlikely NeP" $(0-18)$ and "probable NeP" $(\geq 19)$, which indicates the patient is at risk of NeP.

Participants reported whether they experienced any physical pain in the last 12 months. Those that answered yes completed the PainDetect. Then, participants reported their pain-related experiences. Next, using a checklist, they selected pains that they had experienced for at least 3 of the last 12 months. Then, participants were asked: "Is the pain that you are experiencing nerve pain?" To ensure comprehension, participants were told: "Nerve pain may be described as the feeling of being pricked with pins and needles, shocked by electricity, or may include numbness, burning, or tingling, and can be due to irritation or damage to the nerve. For example, nerve pain from diabetes is often experienced as burning or tingling, and can be due to irritation or damage to the nerve."

They were then supplied with a checklist that included the same pain types and asked to indicate yes or no for each. Additionally, participants also reported the duration of each pain type by indicating whether it was less than 1 year, between 1 and 5 years, or longer than 5 years. Finally, participants were asked to report the medications they were taking if they experienced nerve pain for at least 3 of the last 12 months. For this item, participants were provided a comprehensive list of medications specified by their trade and generic names and space to report medications not on the list. The medications were then categorized into 13 classes using the Institute of Medicine's taxonomy ${ }^{32}$ (Table S1).

\section{Statistical analyses}

The study was designed to estimate the prevalence of probable NeP by demographic strata. To achieve this objective, older (65 years and above) and minority respondents were oversampled. Sampling weights were calculated to adjust the proportions of demographic strata so that the rate aligned with the June 2015 Current Population Survey of the US Census. $^{33}$

Frequencies for the sample and the US population were calculated for sociodemographic variables, questionnaire modality, and region of residence. This was followed by calculation of the PainDetect scores and categorization of respondents into probable $\mathrm{NeP}$ and unlikely NeP groups. Then, weighted generalized linear models specifying a binomial distribution and controlling for age, sex, and race/ ethnicity were used to estimate the adjusted mean percentages of those experiencing $\mathrm{NeP}$ by different questionnaire modality. A heat map was used to demonstrate the prevalence of probable NeP across sex, race, and age. Population estimates were used to report the proportions of the population with probable NeP and unlikely NeP by sex, age, race/ethnicity, and region of residence. Then, population estimates for comorbidity (physical and psychiatric) and pain type were derived for those with probable NeP and unlikely NeP. Next, means for the strongest and average pain items from the PainDetect were compared for those with probable and unlikely $\mathrm{NeP}$ and who had reported nerve pain for at least 3 of the last 12 months. Then, the frequency and percentage for duration of each pain type was calculated. Finally, population estimates of medication use were reported for those who reported NeP pain and those with likely NeP and self-reported NeP pain using the Institute of Medicine's taxonomy. 32

Corresponding 95\% confidence intervals (CIs) are reported when appropriate. The majority of data were collected via Internet questionnaire, which did not allow for skipping items; therefore, analyses were performed on those with completed questionnaires. All analyses were conducted using SAS 9.3.

\section{Results}

\section{Prevalence of probable NeP}

A total of 24,925 respondents were recruited using all five recruitment methods: Internet 15,088 (response rate $2.9 \%$ ), mail 982 (response rate 1.2\%), telephone 2,907 (response rate $1.6 \%$ ), mall intercept 5,338, and store receipt 590 (response rate $0.3 \%$ ). The average response rate was $2.5 \%$. Over half (52.2\%) of the respondents were female, and the mean age was 51.5 years (see Table 1). Almost two-thirds $(63.7 \%)$ of respondents reported they had experienced some form of physical pain in the past 12 months and 
completed the PainDetect to assess the presence of probable $\mathrm{NeP}$ (see Figure 1). The distribution of PainDetect scores is shown in Figure 2 (mean 10.2, median 8). Among those who reported at least some pain in the past 12 months, a weighted estimate of $15.7 \%$ (95\% CI 14.9\%-16.5\%) had probable NeP. This corresponded to a weighted probable NeP-prevalence estimate of 10\% (95\% CI 9.5\%-10.5\%) among all respondents.

The recruitment methods produced generally consistent prevalence estimates for probable $\mathrm{NeP}$ among adults experiencing pain (11.3\%-17.2\%). The calculated rate in the overall population was substantially more variable, and ranged from $4.1 \%$ to $12.4 \%$ (see Table 2 ). There was substantial variation across demographic strata, as demonstrated in the heat map in Figure 3. Among adults experiencing any pain, probable $\mathrm{NeP}$ was most frequent among Hispanic males 35-44 years

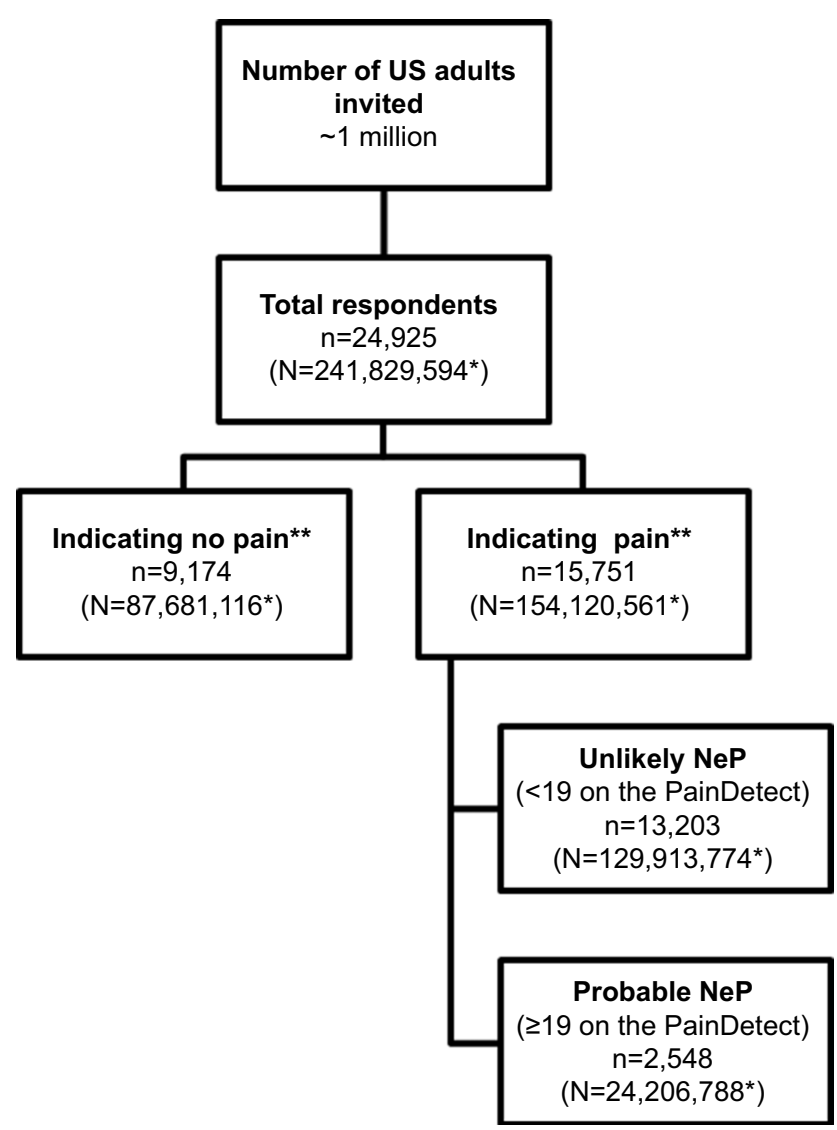

Figure I Study flowchart.

Notes: *Weighted data represent the frequency of the sample data after applying sampling weights, which were calculated by incorporating the age, sex, and race/ ethnicity of the respondents. The US population is based on the most recent Current Population Survey (June 2015) conducted by the US Census Bureau. **Based on the self-reported question, "Have you experienced any physical pain in the last 12 months?" Patients who responded "Yes" were categorized as having pain for this study. Uppercase $\mathrm{N}$ refers to the US population, while lowercase $\mathrm{n}$ refers to the sample.

Abbreviation: NeP, neuropathic pain. old (32.4\%), Hispanic males 45-54 years old (24.2\%), and non-Hispanic Black females 45-54 years old (24.1\%).

\section{Patient characteristics associated with probable $\mathrm{NeP}$ versus unlikely $\mathrm{NeP}$}

The demographic composition of the probable and unlikely $\mathrm{NeP}$ groups were similar across sex; however, the probable$\mathrm{NeP}$ group tended to be younger. The probable-NeP group included more minority participants in general and a much larger percentage of Hispanics. Most participants were from the South, but the probable-NeP group had fewer participants from the Midwest (see Table 3). Respondents with probable $\mathrm{NeP}$ reported higher rates of psychiatric-related comorbidities compared with those unlikely to have $\mathrm{NeP}$, such as anxiety (38\% vs $25.1 \%$ ), depression ( $34.5 \%$ vs $21.1 \%$ ), insomnia ( $34.2 \%$ vs $24.7 \%)$, and pain-related conditions like fibromyalgia (10.1\% vs $2.6 \%)$ and rheumatoid arthritis $(14.5 \%$ vs 3.9\%; see Figure 4).

Additionally, respondents with probable $\mathrm{NeP}$ reported higher rates of all pain types (see Figure 5). For example, those with probable NeP reported higher rates of arthritis/ joint pain (48\%), back pain (BP) (69.9\%), and dental/facial pain $(21.3 \%)$ compared to those with unlikely NeP, who reported rates of $35.4 \%, 52.9 \%$ and $13 \%$, respectively, for the same conditions. Some of the largest differences were observed for diabetes-related pain $(47.9 \%$ vs $20 \%$ among those with diabetes), spinal cord-injury pain $(8.9 \%$ vs $1.5 \%)$, shingles-related pain ( $4.6 \%$ vs $0.9 \%)$, and surgical pain $(12.5 \%$ vs $5.6 \%)$.

\section{Self-reported nerve pain and medication use}

Those who reported nerve pain for at least 3 of the last 12 months and probable $\mathrm{NeP}(\mathrm{n}=2,177)$ had higher scores on PainDetect items assessing the strongest pain (mean 8.35, 95\% CI 8.29-8.43) and average pain (mean 7.13, 95\% CI 7.06-7.2) than unlikely NeP respondents who also reported nerve pain for at least 3 of the last 12 months ( $\mathrm{n}=6,155$; strongest pain, mean $6.8,95 \%$ CI 6.74-6.86; average pain, mean $5.06,95 \%$ CI 5-5.11). The majority of participants with probable $\mathrm{NeP}$ reported pain duration (Table 4 ) of more than 5 years for six of the eleven pain types (arthritis/joint pain, BP, headache/migraine, spinal cord injury, trauma, and other). For three pain types, the majority of participants with probable $\mathrm{NeP}$ reported dental/facial pain, shingles, and surgical pain for less than 1 year. Two pain types included a majority of probable NeP respondents who reported experiencing pain for 1-5 years: diabetes-related pain and pelvic pain. 


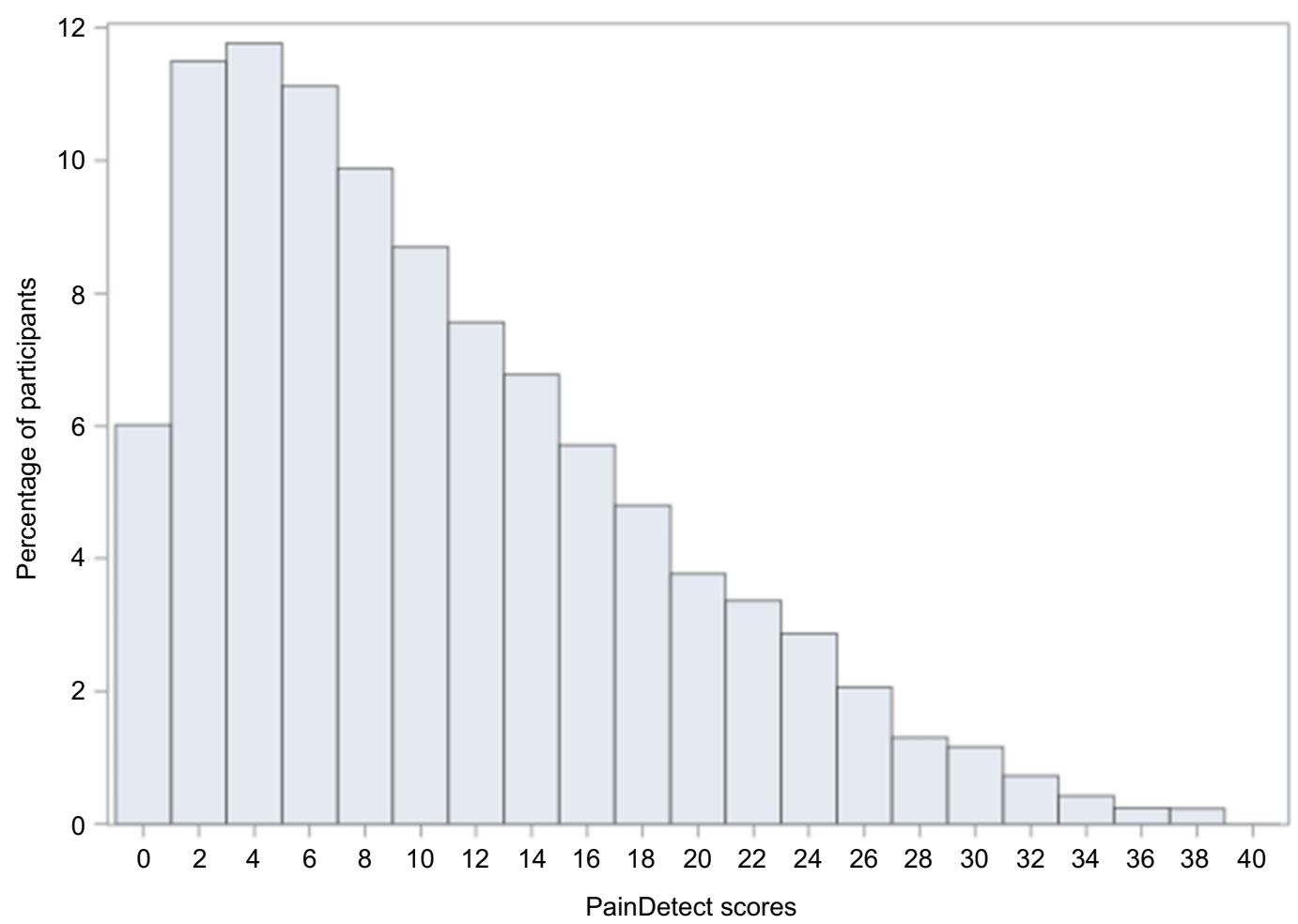

Figure 2 Distribution of PainDetect scores among those with pain $(n=15,749)$.

Notes: Higher scores indicate increased likelihood of neuropathic pain. Respondents who did not self-report experiencing any pain in the past 12 months did not complete the PainDetect $(n=9,174)$. Two respondents with pain in the past 12 months did not complete the PainDetect, and were not included in the PainDetect analyses.

Table 2 Prevalence of NeP based on the PainDetect among all respondents and all respondents with pain by survey modality

\begin{tabular}{|c|c|c|c|c|}
\hline \multirow[t]{2}{*}{ Modality } & \multicolumn{2}{|c|}{ Among all adults (\%) } & \multicolumn{2}{|c|}{$\begin{array}{l}\text { Among all adults } \\
\text { with any pain (\%) }\end{array}$} \\
\hline & Mean & $95 \% \mathrm{Cl}$ & Mean & $95 \% \mathrm{Cl}$ \\
\hline Internet & 10.8 & $(10.3-11.3)$ & 17.2 & $(16.5-18)$ \\
\hline Mail & 8.7 & $(7.2-10.8)$ & 11.3 & $(9.3-13.8)$ \\
\hline Mall intercept & 12.4 & $(11.5-13.3)$ & 15.3 & $(14.3-16.4)$ \\
\hline Store receipt & 8.6 & $(6.6-11.2)$ & 12.2 & $(9.4-15.7)$ \\
\hline Telephone & 4.1 & $(3.4-4.8)$ & 15.4 & $(13.1-18.1)$ \\
\hline
\end{tabular}

Notes: Prevalence was estimated using a sample-weighted generalized linear model, controlling for age, sex, and race/ethnicity, and specifying a binomial distribution; models controlled for age, sex, and race/ethnicity, since different modalities were used to attract different demographic strata.

Abbreviations: $\mathrm{NeP}$, neuropathic pain; $\mathrm{Cl}$, confidence interval.

Among respondents reporting nerve pain for at least 3 of the last 12 months, the most commonly reported medication was nonsteroidal anti-inflammatory drugs (48\%), followed by weak opioids (32.1\%), antiepileptics (11.5\%), strong opioids (11.1\%), and muscle relaxants (10\%). Respondents with probable NeP and self-reported nerve pain for at least 3 of the last 12 months reported taking fewer nonsteroidal anti-inflammatory drugs $(41.7 \%)$, but more weak opioids (43.1\%) and nearly twice the rate of strong opioids (20.9\%), muscle relaxants (19.7\%), and all adjuvant medications, including antiepileptics (20.2\%), antidepressants (12.4\%), and $N$-methyl-d-aspartate antagonists $(0.9 \%)$. "Other" (3\%) included acetaminophen and herbal supplements (see Table 5).

\section{Discussion}

Although some studies have examined the prevalence of broad NeP in Europe, ${ }^{14,26-30}$ to our knowledge this is the first study to provide an estimate of the prevalence of probable $\mathrm{NeP}$ in the US. A total of 15,751 (63.7\%) respondents reported experiencing some pain in the past 12 months, and based on PainDetect scores a weighted estimate of $15.7 \%$ had probable NeP. This corresponded to a probable-NeP prevalence of $10 \%$ in the US population. The proportion of people reporting pain in this study was higher than other studies, such as the National Health Interview Survey, which found that $56 \%$ of adults reported pain, ${ }^{34}$ and the Gallup-Healthways survey, which found that $47 \%$ of adults reported pain. ${ }^{35}$ These disparities may be related to methodological differences. For example, the prevalence identified in the National Health Interview Survey was likely lower because participants were asked to report pain within the last 3 months, rather than a year, as in our study. Nevertheless, the findings reported in 


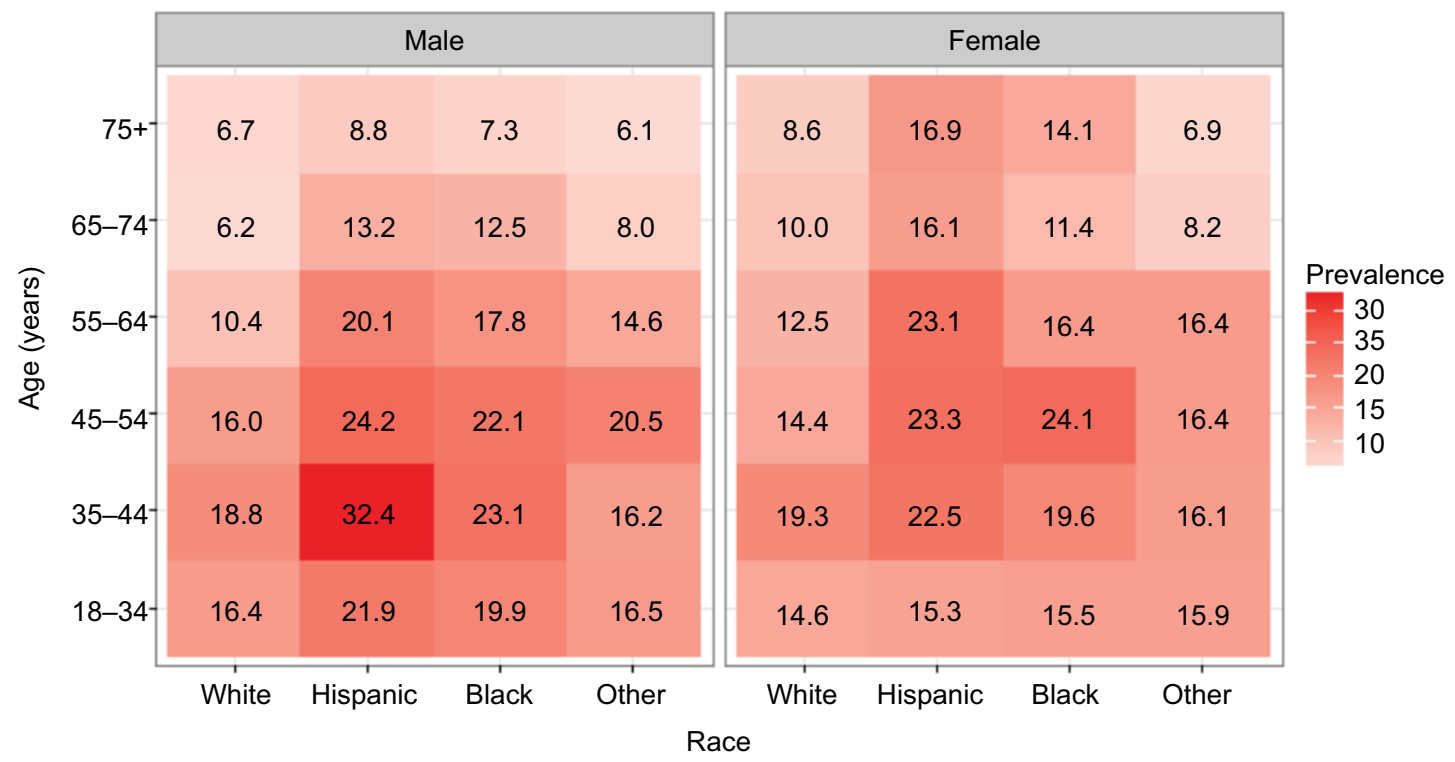

Figure 3 Heat map of the weighted prevalence of probable neuropathic pain, based on the PainDetect, among those with pain by demographic strata.

Table 3 Weighted demographic characteristics among respondents with probable NeP and respondents with pain but unlikely NeP

\begin{tabular}{|c|c|c|c|c|}
\hline \multirow[t]{3}{*}{$\begin{array}{l}\text { Demographic } \\
\text { characteristics }\end{array}$} & \multicolumn{2}{|c|}{$\begin{array}{l}\text { Unlikely NeP } \\
\text { (PainDetect < 19) }\end{array}$} & \multicolumn{2}{|c|}{$\begin{array}{l}\text { Probable NeP } \\
\text { (PainDetect } \geq 19)\end{array}$} \\
\hline & \multicolumn{2}{|c|}{$N=|29,9| 3,774$} & \multicolumn{2}{|c|}{$N=24,206,788$} \\
\hline & $\mathbf{n}$ & $\%(95 \% \mathrm{Cl})$ & $\mathbf{n}$ & $\%(95 \% \mathrm{Cl})$ \\
\hline \multicolumn{5}{|l|}{ Sex (\%) } \\
\hline Male & $61,765,757$ & $47.6(46.4-48.8)$ & $12,0 \mid 3,398$ & $49.6(46.9-52.3)$ \\
\hline Female & $68,148,016$ & $52.5(51.3-53.7)$ & $12,193,390$ & $50.4(47.7-53.1)$ \\
\hline \multicolumn{5}{|l|}{ Age, years (\%) } \\
\hline $18-34$ & $4|| 37,388$, & $31.7(30.5-32.9)$ & $8,177,056$ & $33.8(3 \mathrm{I} . \mathrm{I}-36.5)$ \\
\hline $35-44$ & $20,038,205$ & $15.4(14.6-16.2)$ & $5,277,625$ & $21.8(19.7-23.9)$ \\
\hline $45-54$ & $22,899,740$ & $17.6(16.7-18.5)$ & $4,947,003$ & $20.4(18.3-22.5)$ \\
\hline $55-64$ & $22,374,378$ & $17.2(16.4-18)$ & $3,481,001$ & $14.4(12.7-16.1)$ \\
\hline $65-74$ & $15,019,395$ & $11.6(11-12)$ & $I, 524,|4|$ & $6.3(5.4-7.2)$ \\
\hline $75+$ & $8,444,667$ & $6.5(5.7-7.3)$ & 799,963 & $3.3(2.5-4.1)$ \\
\hline \multicolumn{5}{|c|}{ Race/ethnicity (\%) } \\
\hline White & $84,905,188$ & $65.4(64.5-66.3)$ & $13,566,229$ & $56(57.1-54.9)$ \\
\hline Hispanic & $19,994,555$ & $15.4(14.8-16)$ & $5,442,44 I$ & $22.5(21.1-23.9)$ \\
\hline Black & $14,940,179$ & $11.5(11-12)$ & $3,372,573$ & $13.9(12.6-15.2)$ \\
\hline Other & $10,073,852$ & $6.5(6.7-7.9)$ & $1,825,545$ & $7.5(6.2-8.8)$ \\
\hline \multicolumn{5}{|l|}{ Region (\%) } \\
\hline Northeast & $23,337,766$ & $18(17.1-18.9)$ & $4,964,442$ & $20.5(18.4-22.6)$ \\
\hline Midwest & $34,302,737$ & $26.4(25.3-27.5)$ & $4,943,089$ & $20.4(18.2-22.6)$ \\
\hline South & $41,166,584$ & $31.7(30.6-32.8)$ & $8,393,247$ & $34.7(32.2-37.2)$ \\
\hline West & $30,772,373$ & $23.7(22.7-24.7)$ & $5,859,445$ & $24.2(21.9-26.5)$ \\
\hline
\end{tabular}

Note: Column percentages are reported, which provides the percentage of respondents in each row who have probable NeP and unlikely NeP.

Abbreviations: $\mathrm{NeP}$, neuropathic pain; $\mathrm{Cl}$, confidence interval.

this study are consistent with the range of NeP estimates identified in previous research. ${ }^{14,15,36-38}$ For example, the projected rate of probable NeP in the Gallup-Healthways survey of US respondents randomly selected from the general population was $7.4 \%,{ }^{35}$ the prevalence of NeP among adult Minnesotans was $9.8 \%,{ }^{15}$ and a systematic review of studies by van Hecke et al found that $\mathrm{NeP}$ prevalence ranged from $6.9 \%$ to $10 \%$, but noted a range of $3 \%-17 \%$ in the 21 studies identified. ${ }^{14}$

In Europe, the prevalence of $\mathrm{NeP}$ ranges from $6.5 \%{ }^{39}$ to $11.8 \%{ }^{40}$ Torrance et al estimated the prevalence of NeP in the general adult population of the UK at $8 \%-9 \%$ using the Leeds Assessment of Neuropathic Symptoms and Signs. ${ }^{36,38}$ 


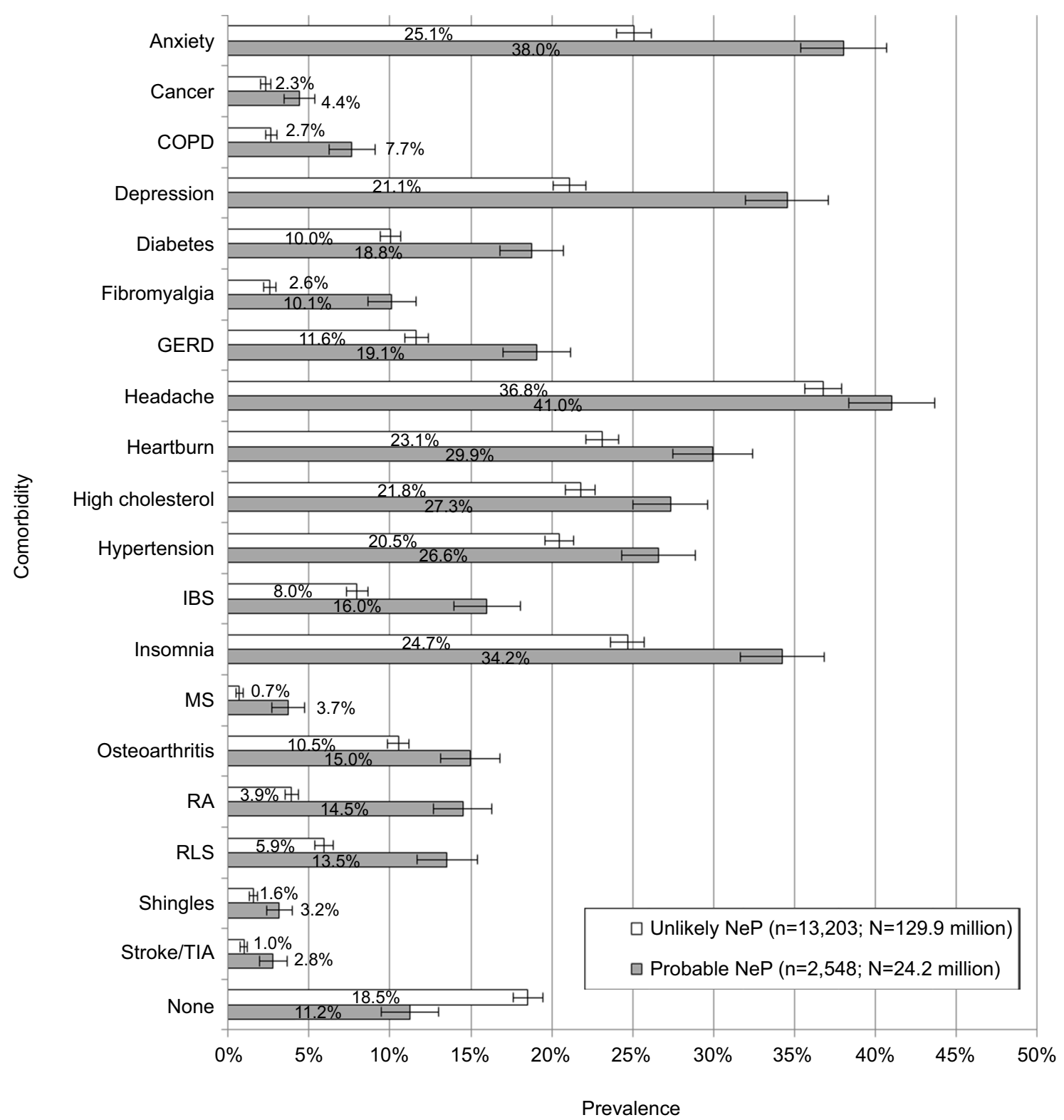

Figure 4 Weighted comorbidity-prevalence estimates among respondents with probable NeP and respondents with pain but unlikely NeP.

Notes: Error bars indicate $95 \%$ confidence intervals.

Abbreviations: COPD, chronic obstructive pulmonary disease; GERD, gastroesophageal reflux disease; IBS, irritable bowel syndrome; MS, multiple sclerosis; NeP, neuropathic pain; RLS, restless leg syndrome; RA, rheumatoid arthritis; TIA, transient ischemic attack.

Bouhassira et al conducted a general-population survey in France using the Douleur Neuropathique 4 (DN4), and found that $6.9 \%$ of the population experienced chronic pain with NeP characteristics. ${ }^{37}$ Similar estimates were reported in Germany (6.5\%) using the DN4 and PainDetect. ${ }^{39}$ A Spanish study of patients treated in the primary care setting reported a slightly higher prevalence of $11.8 \%$ for $\mathrm{NeP}$ based on clinical assessment. ${ }^{40}$

Substantial variation was observed with respect to age and ethnicity. The finding that prevalence of probable $\mathrm{NeP}$ was highest among middle-aged Hispanics was unexpected, but there is some precedence for this finding. Prior research has found that severe pain and pain interference is more common among Hispanics and non-Hispanic Blacks than non-Hispanic Whites ${ }^{41}$ Further, Hispanics with NeP reported more severe pain than non-Hispanic Whites. ${ }^{42}$

With respect to our finding of $\mathrm{NeP}$ peaking in middle age, Bouhassira et al also observed the same effect using the DN4 diagnostic tool to assess NeP. ${ }^{37}$ Other studies in Finland and the Netherlands have found prevalence to be higher among older persons. ${ }^{43,44}$ The reason for this discrepancy is unclear. A possible explanation is that the US has a higher incidence of type II diabetes than Europe, which could result in increased levels of DPN and thus a younger 


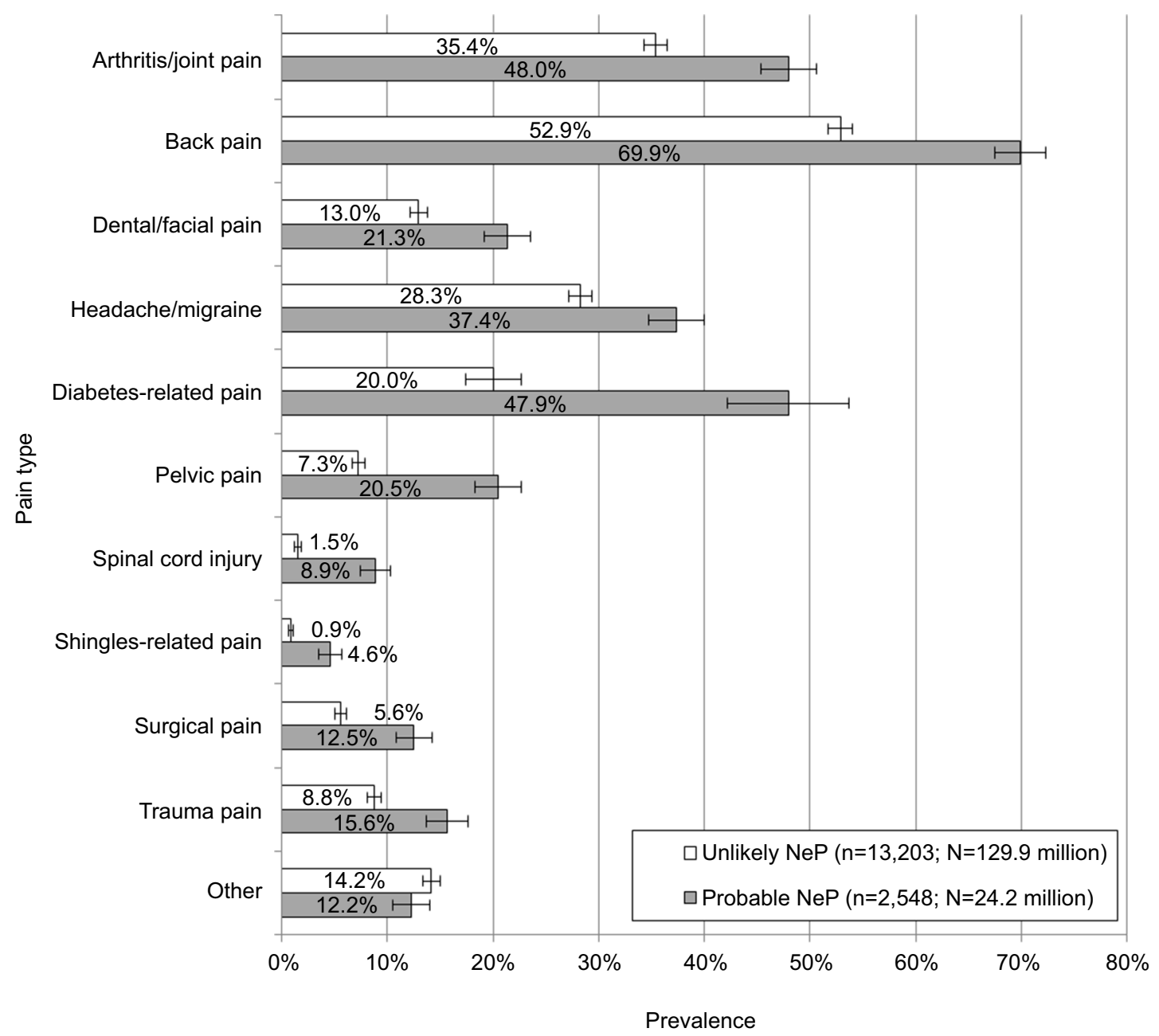

Figure 5 Weighted pain-type prevalence among respondents with probable $\mathrm{NeP}$ and respondents with pain but unlikely NeP.

Notes: Percentage based on those who self-reported having diabetes. Error bars indicate $95 \%$ confidence intervals. All pain types were significantly different between groups, with the exception of "Other" $(P=0.062)$.

Abbreviation: $\mathrm{NeP}$, neuropathic pain.

population with $\mathrm{NeP}^{45}$ Studies have shown that surgery rates for CLBP, which can result in NeP, are substantially higher in the US than Europe. ${ }^{11}$ It is also possible that the higher rates of obesity in the US compared to Europe may be causing NeP-related conditions like diabetes and CLBP to occur earlier. ${ }^{46,47}$

The results also suggest a significant comorbidity burden among respondents with probable NeP. The greatest differences between those with probable $\mathrm{NeP}$ and those unlikely to have it were observed for psychiatric, sleep disorder, and pain-related conditions. This finding is consistent with research conducted in other regions, and highlights the strong interrelationships between pain and mood. ${ }^{48-50}$ Additionally, the biggest differences in the pain types reported between respondents with probable $\mathrm{NeP}$ and those unlikely to have $\mathrm{NeP}$ were for pain types that were predominantly neuropathic in origin (eg, diabetes-related pain, spinal cord-injury pain, and shingles-related pain), indicating some convergence between their responses on the PainDetect and the condition reported.

Nevertheless, there were respondents with probable NeP who reported pain types not typically associated with neuropathic symptoms. This finding is consistent with previous work. A different set of studies was conducted to determine the clinical presentation and burden of illness in six different $\mathrm{NeP}$ conditions: HIV NeP, ${ }^{51}$ posttrauma/postsurgical $\mathrm{NeP},{ }^{52}$ spinal cord injury with $\mathrm{NeP}{ }^{53} \mathrm{CLBP}^{42}$ painful diabetic neuropathy ${ }^{54}$ and painful peripheral neuropathy with small-fiber involvement. ${ }^{42}$ In these studies, physicians and patients were required to answer questions regarding NeP, comorbid medical and psychiatric conditions, and medication to treat $\mathrm{NeP}$. These studies noted an increased incidence of medical and psychiatric conditions that were a function of pain severity. These medical conditions included other NeP conditions, fibromyalgia, restless-leg syndrome, and painful conditions 
typically thought to be nociceptive, such as rheumatoid arthritis. Therefore, it is not surprising that patients with NeP report an increased incidence of other painful conditions, regardless of their origin. ${ }^{42,51-55}$ It is also possible that the $80 \%$ specificity ${ }^{22}$ of PainDetect coded some nociceptive patients as false-positive NeP patients. If our findings are corroborated

Table 4 Respondents' duration of pain by pain type

\begin{tabular}{|c|c|c|c|c|}
\hline \multirow[t]{3}{*}{ Pain type } & & \multicolumn{3}{|c|}{ Probable NeP (PainDetect $\geq 19$ ) } \\
\hline & & $<$ I year & $1-<5$ years & $5+$ years \\
\hline & & \multicolumn{3}{|c|}{$N=24,206,788$} \\
\hline \multirow[t]{2}{*}{ Arthritis/joint pain } & $\mathrm{n}$ & $\mathrm{I}, 880,793$ & $4,350,453$ & $5,315,768$ \\
\hline & $\%$ & $16.29 \%$ & $37.68 \%$ & $46.04 \%$ \\
\hline \multirow[t]{2}{*}{ Back pain } & $\mathrm{n}$ & $2,967,346$ & $6,073,593$ & $7,808,091$ \\
\hline & $\%$ & $17.61 \%$ & $36.05 \%$ & $46.34 \%$ \\
\hline \multirow[t]{2}{*}{ Dental/facial pain } & $\mathrm{n}$ & $2,404,032$ & $\mathrm{I}, 565,175$ & $1,172,127$ \\
\hline & $\%$ & $46.76 \%$ & $30.44 \%$ & $22.8 \%$ \\
\hline \multirow[t]{2}{*}{ Headache/migraine } & $\mathrm{n}$ & $1,687,695$ & $2,697,547$ & $4,576,751$ \\
\hline & $\%$ & $18.83 \%$ & $30.1 \%$ & $51.07 \%$ \\
\hline \multirow[t]{2}{*}{ Diabetes-related pain } & $\mathrm{n}$ & 384,435 & 901,935 & 832,384 \\
\hline & $\%$ & $18.14 \%$ & $42.57 \%$ & $39.29 \%$ \\
\hline \multirow[t]{2}{*}{ Pelvic pain } & $\mathrm{n}$ & $1,403,749$ & $\mathrm{I}, 873,945$ & $1,566,012$ \\
\hline & $\%$ & $28.98 \%$ & $38.69 \%$ & $32.33 \%$ \\
\hline \multirow[t]{2}{*}{ Spinal cord injury } & $\mathrm{n}$ & 464,685 & 690,022 & 978,399 \\
\hline & $\%$ & $21.78 \%$ & $32.35 \%$ & $45.87 \%$ \\
\hline \multirow[t]{2}{*}{ Shingles } & $\mathrm{n}$ & 432,924 & $405,7 \mid 4$ & 240,809 \\
\hline & $\%$ & $40.11 \%$ & $37.59 \%$ & $22.31 \%$ \\
\hline \multirow[t]{2}{*}{ Surgical } & $\mathrm{n}$ & $\mathrm{I}, 303,247$ & 927,156 & 762,799 \\
\hline & $\%$ & $43.54 \%$ & $30.98 \%$ & $25.48 \%$ \\
\hline \multirow[t]{2}{*}{ Trauma pain } & $\mathrm{n}$ & 918,365 & 922,028 & $\mathrm{I}, 890,530$ \\
\hline & $\%$ & $24.61 \%$ & $24.71 \%$ & $50.67 \%$ \\
\hline \multirow[t]{2}{*}{ Other } & $\mathrm{n}$ & 483,577 & 852,812 & $\mathrm{I}, 497,146$ \\
\hline & $\%$ & $17.07 \%$ & $30.1 \%$ & $52.84 \%$ \\
\hline
\end{tabular}

Abbreviation: NeP, neuropathic pain. in future studies, this has important implications for general pain management and treatment.

\section{Limitations}

Although data were obtained from 24,925 respondents, the response rate was very low compared to studies with Internet recruitment (they tend to be $20 \%-30 \%$ ), but those studies did not attempt to estimate prevalence. ${ }^{56}$ However, the low response rate could have resulted in a bias toward respondents who have more painful illnesses than those who chose not to participate, which is evidenced by the finding that the overall rates of pain reported in this study were higher than other studies. ${ }^{34,35}$ The finding that middle-aged respondents reported higher levels of $\mathrm{NeP}$ may also be the result of a self-selection bias; older respondents with NeP could have disproportionately chosen to forgo study participation.

Further, the PainDetect is a screening tool, and the validation studies focused on patients with clear symptomatology. However, it has not been tested in every potential NeP pain (eg, headache). Further, while it might perform well in largescale epidemiological studies, such as this one, the psychometric properties of the measure have only been examined in studies using selective samples and specific subtypes of NeP. Therefore, it is possible that participants responded in an unexpected manner that may have resulted in an overestimation of prevalence rates. ${ }^{22}$ Additionally, the diagnosis of NeP cannot replace a thorough clinical assessment. Therefore, it is possible assessments by trained health care providers may yield a different prevalence rate for overall NeP.

Table 5 Current NeP-medication use by respondents who self-reported experiencing nerve pain for at least 3 months

\begin{tabular}{|c|c|c|c|c|c|c|}
\hline \multirow[t]{3}{*}{ NeP-medication } & \multicolumn{3}{|c|}{ All respondents self-reporting nerve pain } & \multicolumn{3}{|c|}{$\begin{array}{l}\text { Probable NeP respondents self-reporting } \\
\text { nerve pain }\end{array}$} \\
\hline & \multicolumn{3}{|c|}{$N=79,876,938$} & \multicolumn{3}{|c|}{$N=20,953,636$} \\
\hline & $\mathbf{n}$ & $\%$ & $95 \% \mathrm{Cl}$ & $\mathbf{n}$ & $\%$ & $95 \% \mathrm{Cl}$ \\
\hline NSAID & $38,342,532$ & 48 & $46.5-49.5$ & $8,738,205$ & 41.7 & $38.9-44.5$ \\
\hline Weak opioid & $25,634,060$ & 32.1 & $30.7-33.4$ & $9,035,284$ & 43.1 & $40.3-46$ \\
\hline Antiepileptic & $9,173,723$ & 11.5 & $10.5-12.4$ & $4,238,701$ & 20.2 & 17.9-22.5 \\
\hline Strong opioid & $8,890,192$ & II.I & $10.2-12.1$ & $4,369,720$ & 20.9 & $18.5-23.2$ \\
\hline Muscle relaxant & $7,955,673$ & 10 & $9.1-10.9$ & $4,|4|, 427$ & 19.7 & $\mid 7.4-22.1$ \\
\hline Tramadol & $5,356,325$ & 6.7 & $6-7.4$ & $2,440,161$ & 11.6 & $9.8-13.5$ \\
\hline SSRI & $5,062,934$ & 6.3 & $5.6-7.1$ & $2,603,209$ & 12.4 & $10.4-14.4$ \\
\hline TCA & $2,640,531$ & 3.3 & $2.8-3.8$ & $1,594,214$ & 7.6 & $6.1-9.2$ \\
\hline SNRI & $2,725,170$ & 3.4 & $2.9-4$ & $|, 584,3| 8$ & 7.6 & $6-9.1$ \\
\hline COX2 inhibitor & $2,293,024$ & 2.9 & $2.4-3.3$ & $1,012,713$ & 4.8 & $3.6-6$ \\
\hline Benzodiazepine & $2,216,143$ & 2.8 & $2.3-3.3$ & $1,284,562$ & 6.1 & $4.7-7.6$ \\
\hline Local anesthetic & $\mathrm{I}, 303,8 \mathrm{I} 4$ & 1.6 & I.2-2 & 560,863 & 2.7 & I.8-3.6 \\
\hline NMDA-receptor antagonist & 330,978 & 0.4 & $0.2-0.6$ & 185,745 & 0.9 & $0.3-1.4$ \\
\hline Other & $3,926,884$ & 5 & $4.3-5.6$ & 631,249 & 3 & $2-4$ \\
\hline
\end{tabular}

Abbreviations: NeP, neuropathic pain; $\mathrm{Cl}$, confidence interval; NSAID, nonsteroidal anti-inflammatory drug; SSRI, selective serotonin-reuptake inhibitor; TCA, tricyclic antidepressant; SNRI, serotonin-norepinephrine reuptake inhibitor; NMDA, N-methyl-d-aspartate. 
Furthermore, all information collected in this study was patient-reported (eg, comorbidities, pain history) and thus subject to recall biases and other self-presentation effects. Additionally, only English-language questionnaires were used, which may have impacted the participation of those who were not fluent speakers of the language.

\section{Conclusion}

Among people in the US reporting at least some pain in the last year, $15.7 \%$ likely had a syndrome with a neuropathic component. This study suggests prevalence estimates may be higher among some ethnic minorities. Increased attention should be placed on the recognition and treatment of $\mathrm{NeP}$ among Hispanics and Blacks, given known health care disparities for pain management ${ }^{57}$ and evidence suggesting their pain severity and $\mathrm{NeP}$ prevalence is higher than Whites. Finally, the management of NeP should be considered in the context of patients' overall pain syndrome and comorbid conditions, as these patients frequently have pain from multiple sources and report higher rates of medical and psychiatric comorbidities.

\section{Acknowledgments}

The authors would like to acknowledge the contributions of $\mathrm{Dr}$ Tim Victor, who provided input into the study design, and Dr Errol Philip, who provided input into the literature review. Dr Victor was a full-time employee of Kantar Health at the time of the study, and Dr Philip was a paid contractor to Kantar Health at the time of the study. This study was sponsored by Pfizer Inc.

The analyses included in this paper were presented at the 35th Annual Scientific Meeting of the American Pain Society, May 11-14, 2016, Austin, TX, USA.

\section{Disclosure}

AS, MH, BP, JCC, and PH are employees of Pfizer Inc. AHA was employed by Pfizer Inc during and after completion and submission of this study. KC and IK are employees of Kantar Health, which was paid by Pfizer for study design, execution, analysis, and manuscript development. MDD was an employee of Kantar Health at the time of this study. BRS, JDM, and JTF were investigators for the study. They were not financially compensated for their collaborative efforts or publication-related activities, but JTF and JDM have previously served as study design consultant for Pfizer and have received investigator initiated grant funding for studies of pain unrelated to this study. JDM has received research funding from Pfizer for clinical research unrelated to this study. The authors report no other conflicts of interest of this work.

\section{References}

1. International Association for the Study of Pain. Neuropathic pain. 2012. Available from: http://www.iasp-pain.org/Education/Content.aspx?It emNumber $=1698 \&$ navItemNumber=576\%20-\%20Neuropathicpain Accessed January 9, 2017.

2. Langley PC, Van Litsenburg C, Cappelleri JC, Carroll D. The burden associated with neuropathic pain in Western Europe. J Med Econ. 2013;16(1):85-95.

3. O'Connor A. Neuropathic pain: quality-of-life impact, costs and cost effectiveness of therapy. Pharmacoeconomics. 2009;27(2):95-112.

4. Bennett MI, Rayment C, Hjermstad M, Aass N, Caraceni A, Kaasa S. Prevalence and aetiology of neuropathic pain in cancer patients: a systematic review. Pain. 2012;153(2):359-365.

5. Argoff CE, Cole BE, Fishbain DA, Irving GA. Diabetic peripheral neuropathic pain: clinical and quality-of-life issues. In: Mayo Clinic Proceedings. 2006;81(4 Suppl):S3-S11.

6. Davies M, Brophy S, Williams R, Taylor A. The prevalence, severity, and impact of painful diabetic peripheral neuropathy in type 2 diabetes. Diabetes Care. 2006;29(7):1518-1522.

7. van Acker K, Bouhassira D, De Bacquer D, et al. Prevalence and impact on quality of life of peripheral neuropathy with or without neuropathic pain in type 1 and type 2 diabetic patients attending hospital outpatients clinics. Diabetes Metab. 2009;35(3):206-213.

8. Schmader KE. Epidemiology and impact on quality of life of postherpetic neuralgia and painful diabetic neuropathy. Clin J Pain. 2002;18(6):350-354.

9. Casellini C, Vinik A. Clinical manifestations and current treatment options for diabetic neuropathies. Endocr Pract. 2007;13(5): $550-566$.

10. Guh DP, Zhang W, Bansback N, Amarsi Z, Birmingham CL, Anis AH. The incidence of co-morbidities related to obesity and overweight: a systematic review and meta-analysis. BMC Public Health. 2009; 9:88.

11. Deyo RA. Fusion surgery for lumbar degenerative disc disease: still more questions than answers. Spine J. 2015;15(2):272-274.

12. Fishbain DA, Cole B, Lewis JE, Gao J. What Is the evidence that neuropathic pain is present in chronic low back pain and soft tissue syndromes? An evidence-based structured review. Pain Med. 2014;15(1):4-15.

13. Thomas DM, Weedermann M, Fuemmeler BF, et al. Dynamic model predicting overweight, obesity, and extreme obesity prevalence trends. Obesity. 2014;22(2):590-597.

14. van Hecke O, Austin SK, Khan RA, Smith BH, Torrance N. Neuropathic pain in the general population: a systematic review of epidemiological studies. Pain. 2014;155(4):654-662.

15. Yawn BP, Wollan PC, Weingarten TN, Watson JC, Hooten WM, Melton LJ 3rd. The prevalence of neuropathic pain: clinical evaluation compared with screening tools in a community population. Pain Med. 2009;10(3):586-593.

16. Lightspeed [website on the Internet]. Available from: http://www. lightspeedresearch.com. Accessed January 9, 2017.

17. Survey Sampling International [website on the Internet]. Available from: https://www.surveysampling.com. Accessed January 9, 2017.

18. Toluna [website on the Internet]. Available from: http://www.tolunagroup.com. Accessed January 9, 2017.

19. Dillman DA. Mail and Internet Surveys - The Tailored Design Method: 2007 Update with New Internet, Visual, and Mixed-Mode Guide. 2nd ed. Hoboken (NJ): John Wiley \& Sons; 2006.

20. Fowler FJ Jr. Survey Research Methods. 5th ed. Thousand Oaks (CA): Sage; 2013.

21. Marketing Systems Group [website on the Internet]. Available from: http://www.m-s-g.com/web/index.aspx. Accessed January 9, 2017.

22. Freynhagen R, Baron R, Gockel U, Tölle TR. PainDetect: a new screening questionnaire to identify neuropathic components in patients with back pain. Curr Med Res Opin. 2006;22(10):1911-1920. 
23. Timmerman H, Wilder-Smith O, van Weel C, Wolff A, Vissers K. Detecting the neuropathic pain component in the clinical setting: a study protocol for validation of screening instruments for the presence of a neuropathic pain component. BMC Neurol. 2014;14:94.

24. Cappelleri JC, Koduru V, Bienen EJ, Sadosky A. A cross-sectional study examining the psychometric properties of the PainDetect measure in neuropathic pain. J Pain Res. 2015;8:159-167.

25. Cappelleri JC, Bienen EJ, Koduru V, Sadosky A. Measurement properties of PainDetect by average pain severity. Clinicoecon Outcomes Res. 2014;6:497-504.

26. Cappelleri JC, Koduru V, Bienen EJ, Sadosky A. Characterizing neuropathic pain profiles: enriching interpretation of PainDetect. Patient Relat Outcome Meas. 2016;7:93-99.

27. Moreton BJ, Tew V, das Nair R, Wheeler M, Walsh DA, Lincoln NB. Pain phenotype in patients with knee osteoarthritis: classification and measurement properties of PainDetect and Self-Report Leeds Assessment of Neuropathic Symptoms and Signs scale in a cross-sectional study. Arthritis Care Res. 2015;67(4):519-528.

28. De Andrés J, Pérez-Cajaraville J, Lopez-Alarcón MD, et al. Cultural adaptation and validation of the PainDetect scale into Spanish. Clin J Pain. 2012;28(3):243-253.

29. Tampin B, Briffa NK, Goucke R, Slater H. Identification of neuropathic pain in patients with neck/upper limb pain: application of a grading system and screening tools. Pain. 2013;154(12):2813-2822.

30. Gauffin J, Hankama T, Kautiainen H, Hannonen P, Haanpää M. Neuropathic pain and use of PainDetect in patients with fibromyalgia: a cohort study. BMC Neurol. 2013;13:21.

31. Junker U, Freynhagen R, Längler K, et al. Paper versus electronic rating scales for pain assessment: a prospective, randomised, cross-over validation study with 200 chronic pain patients. Curr Med Res Opin. 2008;24(6):1797-1806.

32. Institute of Medicine. Relieving Pain in America: A Blueprint for Transforming Prevention, Care, Education, and Research. Washington: National Academies Press; 2011.

33. TheDataWeb [website on the Internet]. Available from: http://thedataweb.rm.census.gov. Accessed January 9, 2017.

34. Nahin RL. Estimates of pain prevalence and severity in adults: United States, 2012. J Pain. 2015;16(8):769-780.

35. Brown A. Chronic pain rates shoot up until Americans reach late $50 \mathrm{~s}$. 2012. Available from: http://www.gallup.com/poll/154169/chronicpain-rates-shoot-until-americans-reach-late-50s.aspx. Accessed April 27, 2017.

36. Torrance N, Ferguson JA, Afolabi E, et al. Neuropathic pain in the community: more under-treated than refractory? Pain. 2013;154(5):690-699.

37. Bouhassira D, Lantéri-Minet M, Attal N, Laurent B, Touboul C. Prevalence of chronic pain with neuropathic characteristics in the general population. Pain. 2008;136(3):380-387.

38. Torrance N, Smith BH, Bennett MI, Lee AJ. The epidemiology of chronic pain of predominantly neuropathic origin: results from a general population survey. J Pain. 2006;7(4):281-289.

39. Ohayon MM, Stingl JC. Prevalence and comorbidity of chronic pain in the German general population. J Psychiatr Res. 2012;46(4):444-450.

40. Pérez C, Saldaña MT, Navarro A, Vilardaga I, Rejas J. Prevalence and characterization of neuropathic pain in a primary-care setting in Spain. Clin Drug Investig. 2009;29(7):441-450.
41. Mossey JM. Defining racial and ethnic disparities in pain management. Clin Orthop Relat Res. 2011;469(7):1859-1870.

42. Schaefer C, Sadosky A, Mann R, et al. Pain severity and the economic burden of neuropathic pain in the United States: BEAT neuropathic pain observational study. Clinicoecon Outcomes Res. 2014;6:483-496.

43. Rapo-Pylkkö S, Haanpää M, Liira H. Neuropathic pain among community-dwelling older people: a clinical study in Finland. Drugs Aging. 2015;32(9):737-742.

44. Kollenburg EG, Lavrijsen J, Verhagen SC, Zuidema SU, Schalkwijk A, Vissers KC. Prevalence, causes, and treatment of neuropathic pain in Dutch nursing home residents: a retrospective chart review. $J \mathrm{Am}$ Geriatr Soc. 2012;60(8):1418-1425.

45. Guariguata L, Whiting DR, Hambleton I, Beagley J, Linnenkamp U, Shaw JE. Global estimates of diabetes prevalence for 2013 and projections for 2035. Diabetes Res Clin Pract. 2014;103(2):137-149.

46. Centers for Disease Control and Prevention. Rates of diagnosed diabetes per 100 civilian, non-institutionalized population, by age, United States, 1980-2014. 2015. Available from: http://www.cdc.gov/ diabetes/statistics/prev/national/figbyage.htm. Accessed January 9, 2017.

47. Burke AL, Mathias JL, Denson LA. Psychological functioning of people living with chronic pain: a meta-analytic review. Br J Clin Psychol. 2015;54(3):345-360.

48. Gerrits MM, van Oppen P, van Marwijk HW, Penninx BW, van der Horst HE. Pain and the onset of depressive and anxiety disorders. Pain. 2014;155(1):53-59.

49. Jain R, Jain S, Raison CL, Maletic V. Painful diabetic neuropathy is more than pain alone: examining the role of anxiety and depression as mediators and complicators. Curr Diab Rep. 2011;11(4):275-284.

50. Lerman SF, Rudich Z, Brill S, Shalev H, Shahar G. Longitudinal associations between depression, anxiety, pain, and pain-related disability in chronic pain patients. Psychosom Med. 2015;77(3):333-341.

51. Mann R, Sadosky A, Schaefer C, et al. Burden of HIV-related neuropathic pain in the United States. $J$ Int Assoc Provid AIDS Care. 2016;15(2):114-125.

52. Parsons B, Schaefer C, Mann R, et al. Economic and humanistic burden of post-trauma and post-surgical neuropathic pain among adults in the United States. J Pain Res. 2013;6:459-469.

53. Mann R, Schaefer C, Sadosky A, et al. Burden of spinal cord injuryrelated neuropathic pain in the United States: retrospective chart review and cross-sectional survey. Spinal Cord. 2013;51(7):564-570.

54. Sadosky A, Schaefer C, Mann R, et al. Burden of illness associated with painful diabetic peripheral neuropathy among adults seeking treatment in the US: results from a retrospective chart review and cross-sectional survey. Diabetes Metab Syndr Obes. 2013;6:79-92.

55. Schaefer C, Mann R, Sadosky A, et al. Burden of illness associated with peripheral and central neuropathic pain among adults seeking treatment in the United States: a patient-centered evaluation. Pain Med. 2014;15(12):2105-2119.

56. Schonlau M, Fricker RD, Elliott MN. Conducting research surveys via e-mail and the web. 2002. Available from: http://www.rand.org/pubs/ monograph_reports/MR1480.html. Accessed January 10, 2017.

57. Anderson KO, Green CR, Payne R. Racial and ethnic disparities in pain: causes and consequences of unequal care. J Pain. 2009;10(12): $1187-1204$. 


\section{Supplementary material}

Table SI Medications participants reported for nerve pain, categorized by class

\begin{tabular}{|c|c|}
\hline Class & Medication \\
\hline \multirow[t]{5}{*}{ Antiepileptics } & Carbamazepine \\
\hline & Lamotrigine \\
\hline & Pregabalin \\
\hline & Topiramate \\
\hline & Zonisamide \\
\hline Benzodiazepine & Diazepam \\
\hline $\operatorname{cox} 2$ & Celecoxib \\
\hline \multirow[t]{2}{*}{ GABA } & Baclofen \\
\hline & Gabapentin \\
\hline Local anesthetics & Lidocaine \\
\hline \multirow[t]{5}{*}{ Muscle relaxants } & Metaxalone \\
\hline & Carisoprodol \\
\hline & Cyclobenzaprine \\
\hline & Methocarbamol \\
\hline & Tizanidine \\
\hline NMDA-receptor antagonists & Ketamine \\
\hline \multirow[t]{5}{*}{ NSAIDs } & Diclofenac \\
\hline & Ibuprofen \\
\hline & Meloxicam \\
\hline & Naproxen \\
\hline & Nabumetone \\
\hline Other & Other \\
\hline \multirow[t]{8}{*}{ SNRIs } & Duloxetine hydrochloride \\
\hline & Milnacipran hydrochloride \\
\hline & Venlafaxine \\
\hline & Citalopram \\
\hline & Escitalopram \\
\hline & Fluoxetine \\
\hline & Paroxetine \\
\hline & Sertraline \\
\hline \multirow[t]{5}{*}{ Strong opioids } & Fentanyl \\
\hline & Hydromorphone hydrochloride \\
\hline & Methadone \\
\hline & Morphine \\
\hline & Oxycodone \\
\hline \multirow[t]{3}{*}{ TCAs } & Amitriptyline $\mathrm{HCl}$ \\
\hline & Desipramine \\
\hline & Imipramine \\
\hline Tramadol & Tramadol \\
\hline \multirow[t]{7}{*}{ Weak opioids } & Acetaminophen with codeine \\
\hline & Codeine \\
\hline & Hydrocodone \\
\hline & Hydrocodone bitartrate/ibuprofen \\
\hline & Hydrocodone with acetaminophen \\
\hline & Hydrocodone with aspirin \\
\hline & Tramadol/acetaminophen \\
\hline
\end{tabular}

Abbreviations: GABA, $\gamma$-aminobutyric acid; NMDA, N-methyl-d-aspartate; NSAIDs, nonsteroidal anti-inflammatory drugs; SNRIs, serotonin-norepinephrine reuptake inhibitors; SSRIs, selective serotonin-reuptake inhibitors; TCAs, tricyclic antidepressants. 
The Journal of Pain Research is an international, peer reviewed, open access, online journal that welcomes laboratory and clinical findings in the fields of pain research and the prevention and management of pain. Original research, reviews, symposium reports, hypothesis formation and commentaries are all considered for publication.
The manuscript management system is completely online and includes a very quick and fair peer-review system, which is all easy to use. Visit http://www.dovepress.com/testimonials.php to read real quotes from published authors. 